Drug Anal Res, 2018; 02, 20-26

\title{
Green analytical method for quantification of Secnidazole in tablets by HPLC-UV
}

\author{
Jéssica Gonçalves de Souza Lima ${ }^{\mathrm{a}}$, Ana Carolina Kogawa* and Hérida Regina Nunes Salgado ${ }^{\mathrm{a}}$ \\ ${ }^{a}$ São Paulo State University (UNESP), School of Pharmaceutical Sciences, Campus Araraquara, São Paulo, Brazil
}

*Corresponding author:ac_kogawa@yahoo.com.br

\begin{abstract}
A simple, rapid, economic and green analytical method was validated for the determination of secnidazole in tablets. The aim was to contribute to the green analytical chemistry since it has low use of organic solvent and low production of toxic waste. For the HPLC-UV method, the mobile phase consisted in a mixture of purified water $+0.7 \%$ acetic acid and ethanol $(78: 22, \mathrm{v} / \mathrm{v})$ at a flow rate of $1.3 \mathrm{~mL} \mathrm{~min}^{-1}$ on a CN Luna column $(250 \times 4.6 \mathrm{~mm}, 5 \mu \mathrm{m}$ particle size $)$. Ultraviolet detection was performed at 318 $\mathrm{nm}$. The method was linear over the concentration range of 5-100 $\mu \mathrm{g} \mathrm{mL}^{-1}(\mathrm{r}=0.9998)$ with limits of detection and quantitation of 0.533 e $1.615 \mu \mathrm{g} \mathrm{mL}^{-1}$, respectively. The precision of the method showed RSD less than $2 \%$. The accuracy determined by the average recoveries was $99.58 \%$. The secnidazole tablets were subjected to oxidation, acid, alkaline, neutral and photolytic degradation as stress conditions and the method was considered as indicative of stability. The method is adequate and safe to be a great alternative in routine quality control analyzes for determination and quantification of secnidazole tablets.
\end{abstract}

Keywords: secnidazole, tablets, HPLC, green analytical chemistry, method validation.

\section{Introduction}

Secnidazole, shown in Figure 1, is chemically designated, according to IUPAC, as (RS) -1- (2-methyl-5-nitro-1Himidazol-21-yl) propan-2-ol. Due it belongs to the group of 5-nitroimidazoles, it has broad-spectrum activity against anaerobic protozoa and many anaerobic and microaerophilic bacteria (1). It has as mechanism of action the ability to penetrate by diffusion in the microorganism suffering subsequent reduction in its nitro group; in the case of parasites, the reduction occurs by the pyruvate-ferridoxin pathway, leading to drug activation (2).

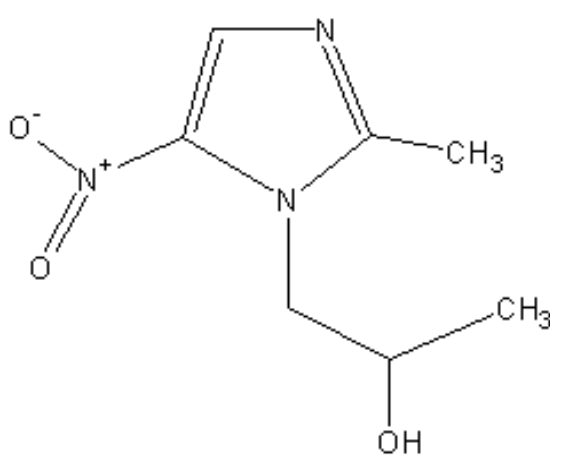

Figure 1. Chemical structure of secnidazole (CAS 3366-95-8).

The high performance liquid chromatography (HPLC) is an analytical technique widely used in analytical laboratories of chemical and pharmaceutical industries for routine analysis of the quality control (3). Among the techniques used in quality control, HPLC is a technique with major advantages since it provides faster analysis, better resolution, greater sensitivity, detectability and precision (4). HPLC has been used to determine secnidazole mostly in pharmaceutical drugs (5-11) and in human blood $(6,12-13)$. In the literature, green analytical methods for secnidazole by HPLC were not found; moreover, the methods use large amount of organic solvents that are toxic to operators and the environment. Nowadays, green analytical methods are relevant and advantageous to industries because it brings less environmental impacts, low analytical costs and higher operator safety. That is why there are many validated physical-chemical and microbiological methods for drugs quantification that apply the concept of green analytical chemistry to help in the environmental preservation, following the same line of this work in cases of HLPC methods that use ethanol and water in the mobile phase (1421).

In the case of HPLC analysis, the use of ethanol instead of solvents such as methanol and acetonitrile reduces the toxicity to the analyst and generates less waste to the environment. The toxicity reduction when ethanol is chosen occurs because methanol generates toxic metabolics in human body, as formaldehyde and formic acid, being a risk to analyst due to daily exposure. Other important fact is that ethanol generates residues that are easily removed, while the acetonitrile, after being incinerated, forms nitrogen residues that contribute to acid rain (22-23). In addition, the use of ethanol and not of the buffer solution in the mobile phase reduces many problems caused to the chromatographic system, especially damage to the analytical column, where the inorganic salts interact largely with silica (24-26). Thus, it was developed in this study a new analytical method by HPLC focused on green analytical chemistry, for quantification of secnidazole in tablets, in order to reduce costs, preserve the environment and greater safety of operators. 
Experimental

\section{Instrumentation and Reagents}

Secnidazole standard, declared content of $99.63 \%$, were kindly provided by the EMS pharmaceutical company (Hortolândia, SP, Brazil). Secnidazole in tablets containing $1000 \mathrm{mg}$ of active substance were used as samples. All solutions and the mobile phase used in this method were prepared from ultrapure water (Millipore ${ }^{\circledR}$, Bedford, MA, USA). HPLC grade ethanol (Panreac ${ }^{\circledR}$, Barcelona, Spain) and HPLC grade acetic acid (J.T. Baker ${ }^{\circledR}$, Phillipsburg, NJ, USA) were used in the mobile phase. After preparation, the mobile phase was submitted to ultrasonic bath for 30 minutes.

\section{Equipment}

The HPLC equipment used was model 1525 Waters (Waters Chromatography Systems, CA, USA), connected to a Waters 2487 UV/Visible detector and manual injector $7725 \mathrm{i}$ (Rheodyne Breeze, CA, USA).

\section{HPLC Method}

HPLC method was carried out in an isocratic mode and the room temperature was maintained at $25{ }^{\circ} \mathrm{C}$. It was used the column Phenomenex Luna CN (250 x $4.60 \mathrm{~mm} ; 5 \mu \mathrm{m}$ particle size). The mobile phase was a mixture of water + $0.7 \%$ acetic acid and ethanol $(78: 22, \mathrm{v} / \mathrm{v})$. The flow rate was $1.3 \mathrm{~mL} \mathrm{~min}^{-1}$. The wavelength used was $318 \mathrm{~nm}$, with an injection volume of $20 \mu \mathrm{L}$. The retention time of secnidazole sample was 4.26 minutes.

\section{Pharmaceutical preparations}

Twenty tablets were accurately weighed, crushed into a fine powder and mixed using a mortar and pestle. A quantity of tablet powder equivalent to $1.000 \mathrm{mg}$ of secnidazole was weighed accurately into a $25 \mathrm{~mL}$ calibrated flask; the diluent solution was added and the mixture was sonicated for 10 min to complete dissolution of the secnidazole; then the mixture was diluted to the mark with the diluent. A portion of the resulting mixture was withdrawn and filtered through a $0.45 \mathrm{~mm}$ filter to ensure the absence of particulate matter. The filtrate was appropriately diluted with the diluent before injection onto the column.

\section{Method Validation}

Method validation was performed according to the parameters established in guidelines (27-32) for linearity, selectivity, accuracy, precision, robustness, detection limit and quantitation limit.

\section{Linearity}

Linearity was evaluated by regression analysis. Sample solutions (5-100 $\mu \mathrm{g} \mathrm{mL}^{-1}$ secnidazole) were injected onto the column in triplicate and the chromatograms were recorded. The equation of the line was determined by linear regression analysis by the method of least squares. Data from the analytical curves were statistically analyzed by Analysis of Variance (ANOVA).

\section{Precision}

The method precision was determined by repeatability precision (intra-assay) and intermediate (inter-assay). The repeatability was performed by the preparation and analysis of six injections of secnidazole at the concentration of $50 \mu \mathrm{g}$ $\mathrm{mL}^{-1}$, on the same day and in the same working conditions. The inter-assay was performed on different days and two different analysts; the first was carried out by the preparation and analysis of six injections of secnidazole in concentration of $50 \mu \mathrm{g} \mathrm{mL} L^{-1}$, in three different days and in the same working conditions; the second was carried out between analysts using the same experimental conditions but by different analysts. Statistical analyses were performed using RSD (\%) values of each test.

\section{Accuracy}

The accuracy of the method was proved by the recovery assay, in which known amounts of secnidazole standard were added to known amounts of secnidazole sample. The recovery assay was conducted at three different levels R1, $\mathrm{R} 2$ and R3, 80, 100 and $120 \%$, respectively, according to ICH recommendations

Aliquots of 5.9, 7.5 and $9.1 \mathrm{~mL}$ of secnidazole standard solution (concentration of $100 \mu \mathrm{g} \mathrm{mL} \mathrm{m}^{-1}$ ) were added, separately, to aliquots of $500 \mu \mathrm{L}$ of the sample solutions (concentration of $100 \mu \mathrm{g} \mathrm{mL} \mathrm{m}^{-1}$ ), resulting in solutions of concentrations $64(\mathrm{R} 1), 80(\mathrm{R} 2)$ and $96(\mathrm{R} 3) \mu \mathrm{g} \mathrm{mL} \mathrm{m}^{-1}$. The concentration of standard solution added to the sample solution was recovered by area values of the chromatographic peak. The recovery was performed in triplicate and the solutions were prepared according to Table 1 .

The recovery percentage $(\mathrm{R} \%)$ was calculated using the Equation 1, which is determined by Association of Official Analytical Chemists (34).

$$
\text { Equation 1: } \% R=\{(\mathrm{Cr}-\mathrm{Ca}) / \mathrm{Cp}\} \times 100
$$

Where:

$\mathrm{Cr}=$ Substance concentration of the standard added sample $\left(\mu \mathrm{g} \mathrm{mL} L^{-1}\right)$ $\mathrm{Ca}=$ Concentration of the sample $\left(\mu \mathrm{g} \mathrm{mL}^{-1}\right)$ $\mathrm{Cp}=$ Theoretical concentration of standard secnidazole added $\left(\mu \mathrm{g} \mathrm{mL} \mathrm{mL}^{-1}\right)$ 
Drug Anal Res, 2018; 02, 20-26

Table 1. Preparation of the secnidazole solutions for the accuracy test by recovery method

\begin{tabular}{ccccc}
\hline & $\begin{array}{c}\text { Secnidazole } \\
\text { sample }(\boldsymbol{\mu L})^{\mathbf{a}}\end{array}$ & $\begin{array}{c}\text { Secnidazole } \\
\text { standard } \\
(\boldsymbol{\mu L})^{\mathbf{a}}\end{array}$ & $\begin{array}{c}\text { Final } \\
\text { theoretical } \\
\text { concentration } \\
\left(\boldsymbol{\mu g} \mathbf{~ m L}^{-1}\right)^{\mathbf{b}}\end{array}$ & $\%$ \\
\hline Sample & 500 & - & 5 & - \\
R1 & 500 & 5900 & 64 & 80 \\
R2 & 500 & 7500 & 80 & 100 \\
R3 & 500 & 9100 & 96 & 120 \\
Standard & - & 500 & 5 & - \\
\hline
\end{tabular}

a-Volumetric flask of $10 \mathrm{~mL} ; \mathrm{b}$-Concentration levels prepared in triplicate

\section{Selectivity}

Selectivity was evaluated by a forced degradation procedure. Secnidazole samples solutions were prepared in $1 \times 10^{-1} \mathrm{~mol}$ $\mathrm{L}^{-1} \mathrm{HCl}, 1 \times 10^{-1} \mathrm{~mol} \mathrm{~L}^{-1} \mathrm{NaOH}$ and $0.3 \% \mathrm{H}_{2} \mathrm{O}_{2}$. The neutral and photolytic conditions were prepared using ultrapure water as solvent. Alkaline, acidic and oxidative samples were heated to $60{ }^{\circ} \mathrm{C}$ for 6 hours. Neutral samples were heated for $80^{\circ} \mathrm{C}$ also for 6 hours and the photolytic samples were exposed to ultraviolet light (UVC, $254 \mathrm{~nm}$ ) at room temperature $\left(25 \pm 2 \quad{ }^{\circ} \mathrm{C}\right)$ for 6 hours. Aliquots of these solutions were taken at 1,3 and $6 \mathrm{~h}$ for all the conditions and the aliquots were analyzed immediately by the HPLC method.

\section{Robustness}

The robustness was evaluated using Youden \& Steiner test (35). The Youden test not only allows to evaluate the robustness of the method, but also to order the influence of each variation on the final results. In this method, 8 assays are performed. The assays are performed separately to determine the effects of variation of 7 different steps $(19,21$, $28,35-37)$. Table 2 shows the variations performed. Upper case letters represent normal working conditions and lower case letters represent small changes. The solutions of $50 \mu \mathrm{g}$ $\mathrm{mL}^{-1}$ of secnidazole tablets were used for each assay.

Table 2. Parameter and variations used in the Youden \& Steiner test to evaluate the robustness of the method

Experiments

\begin{tabular}{|c|c|c|c|c|c|c|c|c|}
\hline Conditions & Normal & Changed & $\begin{array}{lll}1 & 2 & 3\end{array}$ & 4 & 5 & 6 & 7 & 8 \\
\hline Wavelenght (nm) & 318 & 320 & A A A & $\mathrm{A}$ & $\mathrm{a}$ & $\mathrm{a}$ & $\mathrm{a}$ & $\mathrm{a}$ \\
\hline Ultrasonic time & 10 & 5 & B $\mathrm{B} \quad \mathrm{b}$ & $\mathrm{b}$ & $\mathrm{B}$ & $\mathrm{B}$ & $\mathrm{b}$ & $\mathrm{b}$ \\
\hline$\%$ of acetic acid & 0.7 & 0.6 & $\mathrm{C} \quad \mathrm{c} \quad \mathrm{C}$ & $\mathrm{c}$ & $\mathrm{C}$ & $\mathrm{c}$ & $\mathrm{C}$ & $\mathrm{c}$ \\
\hline $\begin{array}{l}\text { Ethanol } \\
\text { proportion in } \\
\text { mobile phase }\end{array}$ & 78 & 75 & $\mathrm{D} d$ & $\mathrm{~d}$ & $\mathrm{~d}$ & $\mathrm{~d}$ & $\mathrm{D}$ & D \\
\hline Flow $\left(\mathrm{mL} / \mathrm{min}^{-1}\right)$ & 1.3 & 1.2 & $E$ e $E$ & $\mathrm{e}$ & $\mathrm{e}$ & $\mathrm{E}$ & $\mathrm{e}$ & $\overline{\mathrm{E}}$ \\
\hline $\begin{array}{l}\text { Injection volume } \\
(\mu \mathrm{L})\end{array}$ & 20 & 18 & $\mathrm{f} f$ & $\mathrm{~F}$ & $\mathrm{~F}$ & $\mathrm{f}$ & $\mathrm{f}$ & $\mathrm{F}$ \\
\hline $\begin{array}{l}\text { Temperature of } \\
\text { room }\left({ }^{\circ} \mathrm{C}\right)\end{array}$ & 24 & 27 & $\mathrm{~g} \quad \mathrm{~g}$ & G & g & G & G & $g$ \\
\hline
\end{tabular}

A, B, C, D, E, F, G = normal conditions

$\mathrm{a}, \mathrm{b}, \mathrm{c}, \mathrm{d}, \mathrm{e}, \mathrm{f}, \mathrm{g}=$ modified conditions

$\mathrm{s}=$ assay using conditions $\mathrm{A}, \mathrm{B}, \mathrm{C}, \mathrm{D}, \mathrm{E}, \mathrm{F}$ and $\mathrm{G}$

$\mathrm{t}=$ assay using conditions $\mathrm{A}, \mathrm{B}, \mathrm{c}, \mathrm{D}, \mathrm{e}, \mathrm{f}$ and $\mathrm{g}$

$\mathrm{u}=$ assay using conditions $\mathrm{A}, \mathrm{b}, \mathrm{C}, \mathrm{d}, \mathrm{E}, \mathrm{f}$ and $\mathrm{g}$

$\mathrm{v}=$ assay using conditions $\mathrm{A}, \mathrm{b}, \mathrm{c}, \mathrm{d}, \mathrm{e}, \mathrm{F}$ and $\mathrm{G}$

$\mathrm{w}=$ assay using conditions $\mathrm{a}, \mathrm{B}, \mathrm{C}, \mathrm{d}, \mathrm{e}, \mathrm{F}$ and $\mathrm{g}$

$\mathrm{x}=$ assay using conditions $\mathrm{a}, \mathrm{B}, \mathrm{c}, \mathrm{d}, \mathrm{E}, \mathrm{f}$ and $\mathrm{G}$

$\mathrm{y}=$ assay using conditions $\mathrm{a}, \mathrm{b}, \mathrm{C}, \mathrm{D}, \mathrm{e}, \mathrm{f}$ and $\mathrm{G}$

$\mathrm{z}=$ assay using conditions $\mathrm{a}, \mathrm{b}, \mathrm{c}, \mathrm{D}, \mathrm{E}, \mathrm{F}$ and $\mathrm{g}$

\section{Limits of detection and quantification}

The limit of detection (LOD) and limit of quantification (LOQ) of the method were obtained from Equations 2 and 3:

Equation 2: LOD: 3.3 o/S

Equation 3: LOQ: 10 o/S

Where:

$\sigma:$ Standard deviation of the response

S: Slope of the calibration curve

\section{Results and discussion}

\section{Linearity}

A standard solution of secnidazole $\left(500 \mu \mathrm{g} \mathrm{mL} \mathrm{mL}^{-1}\right)$ was appropriately diluted with the diluent solution to obtain solutions in the concentration range of $5-100 \mu \mathrm{g} \mathrm{mL} \mathrm{m}^{-1}$. Twenty microliters of each solution were injected in triplicate into the column under the previously described chromatographic

conditions.

The equation of the line, determined by the method of least squares, is $\mathrm{y}=37893 \mathrm{x}-8247.1$, with a correlation coefficient (r) equals to 0.9996 (Figure 2). ANOVA did not presented significant linearity deviation at a $5 \%$ level of variance by presenting a calculated value $F(0.54)$ lower than the critical value $F(3.26)$.

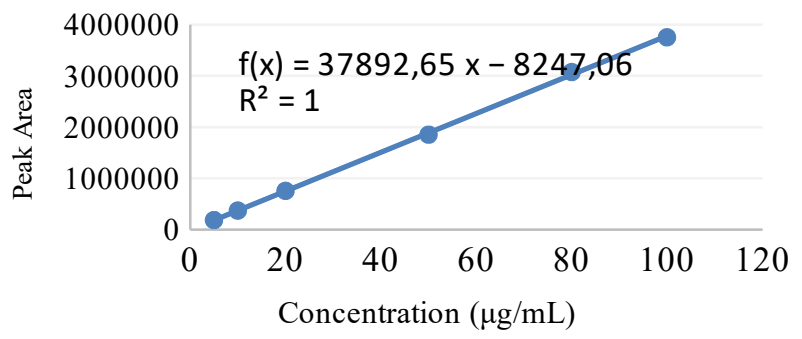

Figure 1. Analytical curve of secnidazole at concentrations of 5$100 \mu \mathrm{g} \mathrm{mL} \mathrm{m}^{-1}$ by validated HPLC method. 


\section{Precision}

For the precision of the method were evaluated intra-assay precision parameters, inter-days and between analysts as showed in Tables 3, 4 and 5. The data showed the suitable precision of the intra-assay, inter-assay and between analysts analysis (RSD values of $0.70 \%, 0.47 \%$ and $1.96 \%$, respectively), since all the RSD values were below the $2 \%$ recommended (38).

Table 3. Determined values for intra-assay precision by HPLC

\begin{tabular}{|c|c|c|c|c|c|c|c|}
\hline & \multicolumn{6}{|c|}{ Peak area } & \multirow[t]{2}{*}{$\begin{array}{l}\text { RSD } \\
(\%)\end{array}$} \\
\hline \multirow{4}{*}{ Day } & 1 & 2 & 3 & 4 & 5 & 6 & \\
\hline & 1855429 & 1827345 & 1868220 & 1847020 & 1871651 & 1853708 & 0.86 \\
\hline & 1853320 & 1848040 & 1875380 & 1879086 & 1856890 & 1853073 & 0.70 \\
\hline & 1783204 & 1882428 & 1888690 & 1901940 & 1875390 & 1895567 & 2.36 \\
\hline
\end{tabular}

Table 4. Determined values for inter-assay precision by HPLC

\begin{tabular}{cccc}
\hline Day & Area $^{a}$ & SD & RSD (\%) \\
\hline 1 & 1853896 & & \\
\hline 2 & 1860965 & 8702 & 0.47 \\
\hline 3 & 1871203 & & \\
\hline
\end{tabular}

${ }^{a}$ Average peak area by six determinations

Table 5. Determined values for precision between two analysts by HPLC

\begin{tabular}{|c|c|c|c|c|c|c|c|}
\hline \multicolumn{7}{|c|}{ Peak height } & \multirow[t]{2}{*}{$\begin{array}{c}\text { RSD } \\
(\%)\end{array}$} \\
\hline & 1 & 2 & 3 & 4 & 5 & 6 & \\
\hline Analyst 1 & 1853320 & 1848040 & 1875380 & 1879086 & 1856890 & 1853073 & \\
\hline Analyst 2 & 1840538 & 1781699 & 1808721 & 1843824 & 1792307 & 1793464 & \\
\hline
\end{tabular}

\section{Accuracy}

The accuracy was performed by recovery through the analysis of three concentrations in the pre-established range. The results of accuracy are shown in the Table 6 . The percentage of recovery was $99.58 \%$, which proves the accuracy of the method and corroborates with the one recommended by Horwitz and collaborators (39) and AOAC (34).

Table 6. Results of the accuracy of the method by HPLC for secnidazole analysis

\begin{tabular}{cccccc}
\hline & $\mathbf{3}$ & $\begin{array}{c}\text { Concentratio } \\
\text { n found of } \\
\text { secnidazole } \\
\left(\boldsymbol{\mu g} \mathbf{~ m L}^{-1}\right)\end{array}$ & $\begin{array}{c}\text { Recover } \\
\mathbf{y}(\%)\end{array}$ & $\begin{array}{c}\text { Average } \\
\text { Recover } \\
\mathbf{y}(\%)\end{array}$ & $\begin{array}{c}\text { RS } \\
\mathbf{( \% )}\end{array}$ \\
\hline $\mathbf{R 1}$ & 59 & 58.07 & 98.42 & & \\
$\mathbf{R 2}$ & 75 & 74.73 & 99.64 & 99.58 & 1.14 \\
$\mathbf{R 3}$ & 91 & 91.63 & 100.69 & & \\
\hline
\end{tabular}

\section{Robustness}

Robustness was analyzed using the Youden Test. Its premise is to introduce many changes at once in order to determine the effect of individual changes. In the analysis performed, only one significant effect, from the flow $\left(\mathrm{mL} \mathrm{min}^{-1}\right)$, was observed in the method when subjected to the proposed changes because its value (8.44) is higher than the calculated effect value (7.59), which is represented by a red line in Figure 3. For all other conditions, the method was considered robust because its effect values were lower than the calculated (7.59).

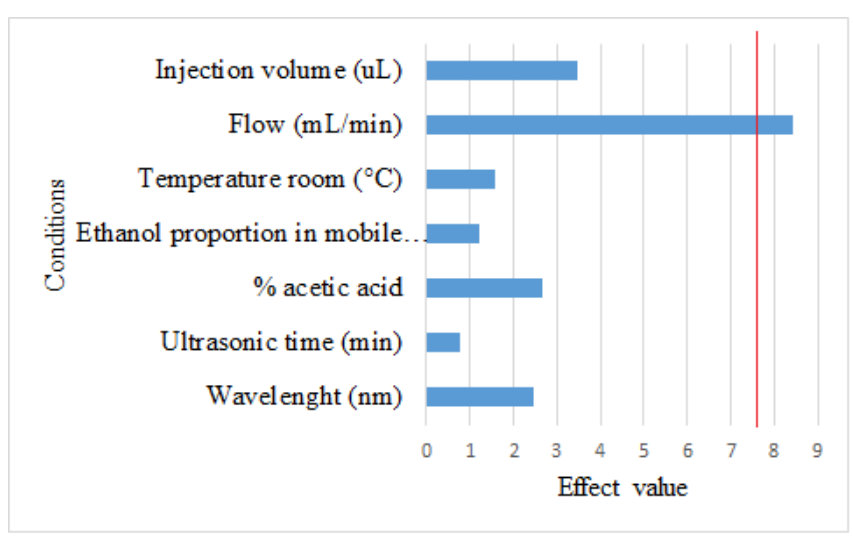

Figure 3. Effect of variations by the Youden test to evaluate the robustness of the method.

\section{Selectivity}

Selectivity was evaluated by a forced degradation procedure or stress test. The Figure 4 show the comparison of the chromatograms obtained for secnidazole sample solution in alkaline (A), acidic (B), water (C), oxidative (D) and photolytic conditions (E). The Figure 5 shows the overlap of chromatograms of secnidazole standard and sample and the adjuvants. 
Drug Anal Res, 2018; 02, 20-26

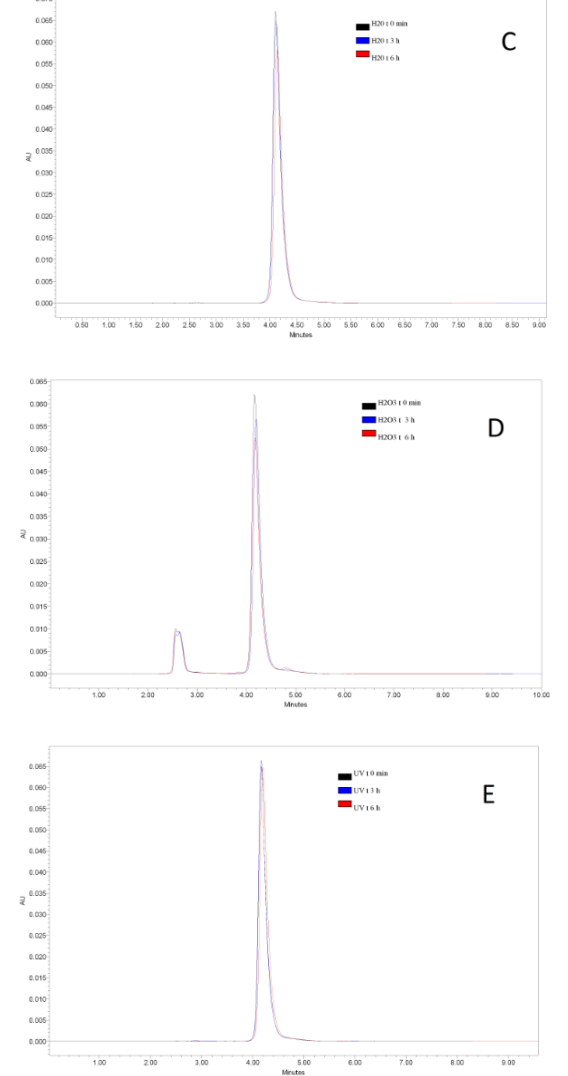

Figure 4. Chromatograms of the degradations of secnidazole in alkaline (A), acidic (B), neutral (C), oxidative (D) and photolytic conditions (E).

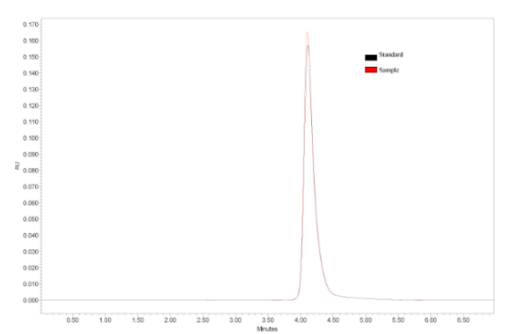

Figure 5. Overlap of chromatograms of secnidazole standard and sample.

The maximum degradation of the drug occurred in alkaline and oxidative conditions. Under alkaline conditions, the area of the secnidazole decreased by $69.13 \%$, showing the great instability of the drug under these conditions. Under oxidative conditions, the reduction in the area was of 83.35 $\%$. The secnidazole did not present degradation under neutral, acidic and photolytic conditions. Thus, the drug was shown to be stable in these conditions. All of these results combined to demonstrate that the method, as well as being selective, is indicative of stability, because it was able to differentiate secnidazole from the other degradation products.

\section{Content of secnidazole in pharmaceutical tablets}

The validated method was applied for the determination of secnidazole in tablets using the line equation obtained in linearity. Samples from $1.000 \mathrm{mg}$ secnidazole tablets were analyzed. The results are in Table 7.

Table 7. Assay of secnidazole in pharmaceutical tablets

\begin{tabular}{|c|c|c|c|c|}
\hline \multirow{2}{*}{ Day } & \multicolumn{2}{|c|}{ Content of secnidazole } & \multirow[t]{2}{*}{ Average (\%) } & \multirow[t]{2}{*}{ RSD (\%) } \\
\hline & $\mu \mathrm{g} \mathrm{mL^{-1 }}$ & $\%$ & & \\
\hline 1 & 47.54 & 95.07 & & \\
\hline 2 & 49.86 & 99.72 & 96.97 & 2.44 \\
\hline 3 & 48.05 & 96.10 & & \\
\hline
\end{tabular}

Analysis of the secnidazole content in tablets using the proposed method was $96.97 \%$. This result is within the specification in the official compendium that recommends content between 95 to $110 \%$ (40).

\section{Conclusions}

A method by reversed-phase liquid chromatography was developed using mobile phase composed of water $+0.7 \%$ acetic acid and ethanol (78:22, v/v) in which all validation parameters were found to be highly satisfactory, including linearity, selectivity, precision, accuracy, robustness and limit of detection and quantification appropriate.

In the official compendia and scientific journals surveyed were not found a method using mobile phase with less toxic solvents for the quantification of secnidazole. Added to this, this method uses lower amounts of organic solvent, does not use buffer solution in mobile phase and produces lower level of waste. Then, it can be considered an innovative and advantageous method in the application of green analytical chemistry, being an alternative ecologically correct and safe to be used in routine analyzes of the quality control.

\section{Acknowledgments}

The authors acknowledge FAPESP \#2017/03906-1 (São Paulo, Brazil), Capes (São Paulo, Brazil) and CNPq (Brasília, Brazil).

\section{Conflict of interest}

The authors declare no conflict of interest.

\section{References}

1. Tripathi, K. D.; Essentials of Medical Pharmacology; Jaypee Brothers Medical Publishers. 7 ed. Bangladesh, 2013.

2. Acar, J., Petitjean, O., Dubreuil, L. Le secnidazole, un nouveau 5-nitro-imidazolé. Antibiotiques 2005; 7:177182. 
Drug Anal Res, 2018; 02, 20-26

3. Kazakevich, Y., Lobrutto, R.; HPLC for Pharmaceutical Scientists; John Wiley \& Sons: New Jersey, 2007.

4. Dong, M. W. The essence of modern HPLC: advantages, limitations, fundamentals, and opportunities. LCGC Separation Science 2013; 31:472-479.

5. Al-kaf, A. G. A., Gadkariem, A. E. R., Algaradi, A. A. S. A., Alssmani, T. Development and validation of an RPHPLC method for estimation of secnidazole and its degradation products in tablets. Global Journal of Pharmacy \& Pharmaceutical Sciences 2016; 1:555552.

6. Alhalabi, Z., Al-khayat, M. A., Haidar, S. Separation and assay of antiprotozoal imidazole derivates (metronidazole, tinidazole and secnidazole) by RPHPLC. International Journal of Pharmaceutical Sciences Review and Research 2012; 13:13-18.

7. Elwalily, A. F. M., Abdine, H. H., Razak, O. A., Zamel, S. Spectrophotometric and HPLC determination of secnidazole in pharmaceutical tablets. Journal of Pharmaceutical and Biomedical Analysis 2000; 22:887897.

8. Farooqui, N. A., Smith, A. A., Sharma, H. K., Manavalan, R. Analytical method development and validation of secnidazole tablets by RP-HPLC. Journal of Pharmaceutical Sciences and Research 2010; 2:412416.

9. Reddy, K. S., Ramachandra B., Naidu, N. V. S. Validation of RP-HPLC method for the estimation of secnidazole in bulk and its pharmaceutical dosage forms. International Journal of Scientific \& Engineering Research 2014; 5:1250-1261.

10.Sharmin, T., Akter, M., Hossain, M. S. Analytical method development and validation of secnidazole in the tablet dosage form by RP-HPLC method. International Current Pharmaceutical Journal 2016; 5:41-44.

11.Suryawanshi, P. P., Khan, P. A., Abhyankar, M., Sonawane, S. S., Gide, P. A validated stability-indicating liquid chromatographic method for secnidazole. Journal of innovations in Pharmaceuticals and Biological $\begin{array}{lll}\text { Sciences } & 2015 ; & 2: 45-52 .\end{array}$

12.Ravi, S. K., Naidu, M. U. R., Sekhar, E. C., Rao, T. R. K., Shobha, J. C., Rani, P. U., Surya, K. J. Rapid and selective analysis of secnidazole in human plasma using high-performance liquid chromatography with ultraviolet detection. Journal of Chromatography B 1996; 691:208211.

13.Li, X., Sun, J., Wang, G., Zheng, Y., Yan, B., Xie, H., Gu, Y., Ren, H. Determination of secnidazole in human plasma by high-performance liquid chromatography with UV detection and its application to the bioequivalence studies. Biomedical Chromatography 2007; 21:304-309.

14.Chierentin, L., Salgado, H. R. N. Development and validationof a simple, rapid and stability-indicating high performance liquid chromatography method for quantification of norfloxacin in a pharmaceutical product. Chromatography Separation Techniques 2013; 4:171-175.

15.Tótoli, E. G., Salgado, H. R. N. Development and validation of an economic, environmental friendly and stability-indicating analytical method for determination of ampicillin sodium for injection by RP-HPLC. World Journal of Pharmacy and Pharmaceutical Sciences 2014; 3:1928-1943.

16.Tótoli, E.G., Salgado, H. R. N. Development, optimization and validation of a green and stabilityindicating HPLC method for determination of daptomycin in lyophilized powder. Journal of AOAC International 2015;

98:1276-1285.

17.Rodrigues, D. F., Salgado, H. R. N. Development and validation of a Green analytical method of RP-HPLC for quantification cefepime hydrochloride in pharmaceutical dosage forms: simple, sensitive and economic. Current Pharmaceutical Analysis 2016; 12:306-314.

18.Spagnol, C. M.; Isaac, V. L.; Corrêa, M. A.; Salgado, H. R. N. Validation of HPLC-UV assay of caffeic acid in emulsions. Journal of Chromatographic Sciences 2016; 54:305-311.

19.Pedroso, T. M.; Medeiros, A. C. D.; Salgado, H. R. N. RP-HPLC $x$ HILIC chromatography for quantifying the ertapenem sodium with a look at green chemistry. Talanta 2016; $\quad 160: 745-753$.

20.Figueiredo, A. L.; Kogawa, A. C.; Salgado, H. R. N. Development and validation of an ecological, new and rapid stability-indicating High Performance Liquid Chromatography for quantitative determination of aztreonam in lyophilized powder for injection. Drug Analytical Research 2017; 1:24-30.

21.Marco, B. A.; Salgado, H. R. N. Development and validation of a green RP-HPLC method for quantification of cefadroxil capsules. World Journal of Pharmacy and Pharmaceutical Sciences 2017; 6:20742091.

22.Kogawa, A. C.; Salgado, H. R. N. Ethanolon HPLC: epiphany or nonsense? Acta Scientific Pharmaceutical Sciences 2018; 2:14-15. 
23.Marco, B. A.; Rechelo, B. S.; Tótoli, E. G.; Kogawa, A. C.; Salgado, H. R. N. Evolution of green chemistry and its multidimensional impacts: a review; Saudi Pharmaceutical Journal DOI 10.1016/j.jsps.2018.07.011.

24.Watson, D. G. Pharmaceutical analysis, Churchill Livingstone:

London,

1999.

25. Ohannesian, L.; Streeter, A. J. Handbook of pharmaceutical analysis, 3rd ed. Marcel Dekker: New York, 2002. 2009;32: 3425-3431.

26.Snyder, L. R.; Kirkland, J. J.; Dolan, J. W. Introduction to Modern Liquid Chromatography, John Wiley \& Sons: New Jersey, 3rd ed., 2010.

27.ICH. International Conference on Harmonization. Validation of analytical procedures: text and methodology Q2(R1), 2005.

28.Inmetro Instituto Nacional de Metodologia de Metrologia, Normalização e Qualidade Industrial. Orientação sobre validação de métodos de ensaios químicos, DOQ-CGCRE-008, 2007.

29.ISO. International Organization for Standardization. General Requirements for the Competence of Testing and Calibration Laboratories, ISSO/IEC 17025, 1999.

30.BRASIL. Agência Nacional de Vigilância Sanitária (ANVISA). RDC n ${ }^{\circ} 166$, de 24 de Julho de 2017. Dispõe sobre a validação de métodos analíticos e dá outras providências. Diário Oficial da União. Brasília, 25 jul. 2017.

31.ICH. International Conference on Harmonizaion. Validation of Analytical Procedures: Methodology Q2B, 1996.

32. Brasil, Agência Nacional de Vigilância Sanitária, RE 899, Guia para validação de métodos analíticos e bioanalíticos,

Brasília,

2003.
33.ICH. International Conference on Harmonization. Validation of analyticalprocedures: text and methodology Q2(R1), 2005.

34.AOAC - Association of Official Analytical Chemists. Official Methods of Analysis. 17. ed. Gaithesburg: AOAC, 2002.

35. Youden, W. J.; Steiner, E. H. Statistical Manual of AOAC - Association of Official Analytical Chemistry. Washington:

AOAC,

1975.

36.Kogawa, A. C.; Mendonça, J. N.; Lopes, N. P.; Salgado, H. R. N. Recent advances in the study of the inclusion complex darunavir: $\beta$-cyclodextrin by LC-MS. Journal of AOAC International 2016; 99:626-637.

37.Pedroso, T. M.; Salgado, H. R. N. Validation of analytical methodology for quantification of cefazolin sodium pharmaceutical dosage form by high performance liquid chromatography to be applied for quality control in pharmaceutical industry. Brazilian Journal of Pharmaceutical Sciences 2014;50:213-223.

38. Shabir, G. A. Validation of high-performance liquid chromatography methods for pharmaceutical analysis: Understanding the differences and similarities between validation requirements of the US Food and Drug Administration, the US Pharmacopeia and the International Conference on Harmonization. Journal of Chromatography A 2003; 987:57-66.

39.Horwitz, W.; Kamps, L. R.; Boyer, K. W. J. Quality assurance in the analysis of foods and trace constituents. Association of Official Analytical Chemists 1980; 63:1344-1354.

40.Indian Pharmacopoeia. RajNagar: Ghaziabad, (2007); 3: 1072-1074. 